\title{
Human blood and bird egg proteins identified in red paint covering a 1,000-year-old gold mask from Peru
}

\author{
Elisabete Pires ${ }^{1}$, Luciana da Costa Carvalho ${ }^{2 *}$, Izumi Shimada ${ }^{3}$ and James McCullagh ${ }^{1}$
}

${ }^{1}$ Mass Spectrometry Research Facility, Department of Chemistry, University of Oxford, Oxford OX1 3TA, UK

${ }^{2}$ School of Archaeology, University of Oxford, Oxford OX1 3TG, UK

${ }^{3}$ Department of Anthropology, Southern Illinois University, Carbondale IL 62901-6899, USA

\section{SUPPORTING INFORMATION}

\section{$\underline{\text { Contents }}$}

Figure S1. Spectral information: Serum albumin (Homo Sapiens)- YIC(+57.02)ENQDSISSK

Figure S2. Spectral information: Immunoglobin G (Homo Sapiens)- AGVETTTPSK

Figure S3. Spectral information: Immunoglobin Kappa constant (Homo Sapiens)-

TVAAPSVFIFPPSDEQLK

Figure S4. Spectral information: Ovoalbumin (fragment) Gallus gallus- ERIEKTIN(+.98)FEK

Figure S5. Spectral information: Ovomucoid (Aquila chrysaetos) -C(+57.02)RLERAQA

ITWNNLQ(+.98)GK

Figure S7. Spectral information: Vitellogenin-2 (Gallus gallus)- S(+43.01)PYEDIQAK 
ms/ms spectrum

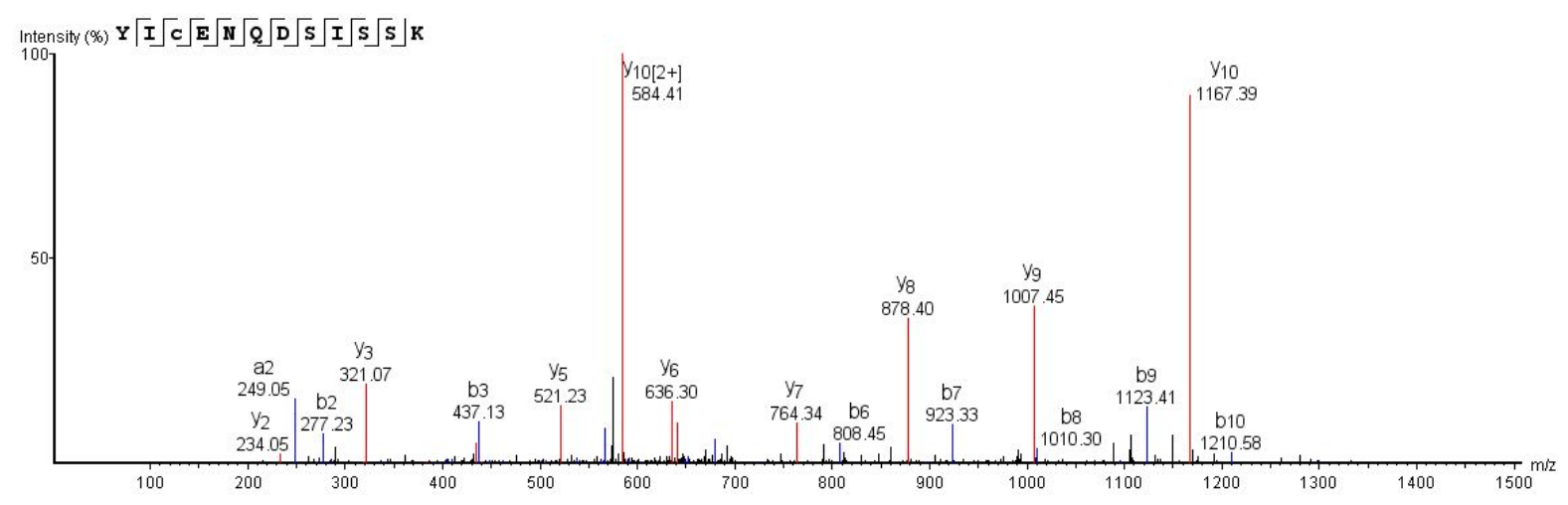

alignment spectrum view

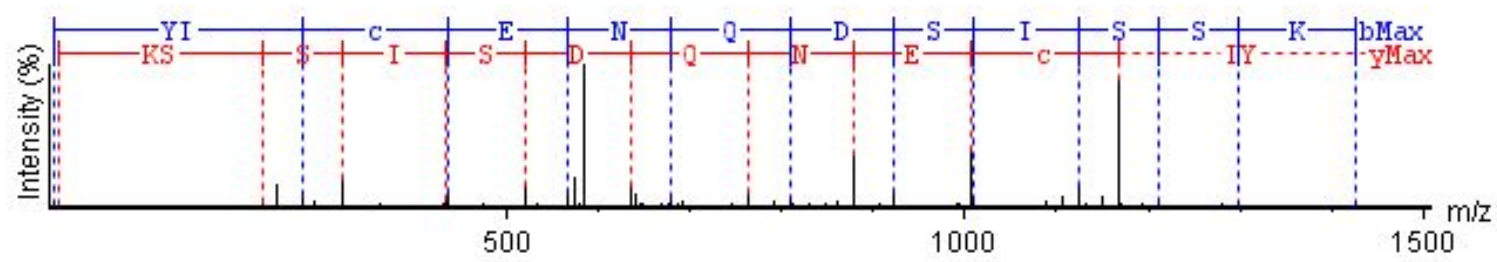

Ion b and y Table and Error Map

\begin{tabular}{|c|c|c|c|c|c|c|c|c|}
\hline$\#$ & b & a & $b(2+)$ & $a(2+)$ & Seq & $y$ & $y(2+)$ & $\#$ \\
\hline 1 & 164.07 & 136.08 & 82.54 & 68.54 & $\mathrm{Y}$ & & & 12 \\
\hline 2 & 277.23 & 249.05 & 139.08 & 125.08 & I & 1280.58 & 641.04 & 11 \\
\hline 3 & 437.13 & 409.38 & 219.09 & 205.10 & $C(+57.02)$ & 1167.39 & 584.41 & 10 \\
\hline 4 & 566.30 & 538.36 & 284.25 & 270.14 & $E$ & 1007.45 & 505.02 & 9 \\
\hline 5 & 680.19 & 651.70 & 341.04 & 326.64 & $\mathrm{~N}$ & 878.40 & 439.86 & 8 \\
\hline 6 & 808.45 & 780.33 & 404.23 & 391.14 & Q & 764.34 & 383.41 & 7 \\
\hline 7 & 923.33 & 895.37 & 462.26 & 448.20 & D & 636.30 & 319.05 & 6 \\
\hline 8 & 1010.30 & 982.39 & 505.71 & 491.70 & S & 521.23 & 261.15 & 5 \\
\hline 9 & 1123.41 & 1095.66 & 562.40 & 548.24 & I & 434.24 & 217.63 & 4 \\
\hline 10 & 1210.58 & 1182.51 & 605.35 & 591.34 & $\mathrm{~S}$ & 321.07 & 161.09 & 3 \\
\hline 11 & 1298.17 & 1269.54 & 648.82 & 635.50 & $\mathrm{~S}$ & 234.05 & 117.57 & 2 \\
\hline 12 & & & & & K & 147.11 & 74.06 & 1 \\
\hline
\end{tabular}

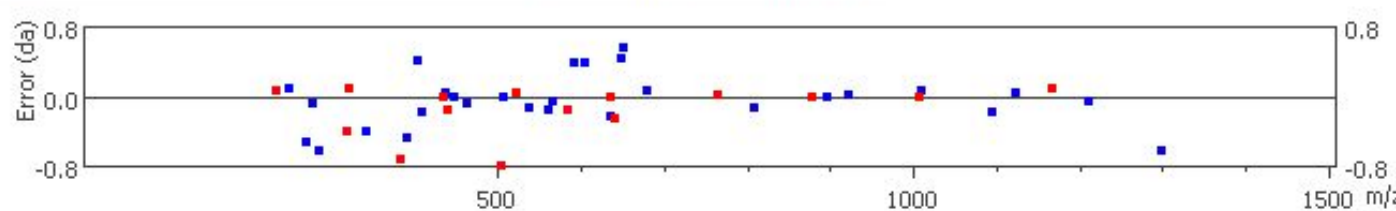

Figure S1. Spectral information: Serum albumin (Homo Sapiens)- YIC(+57.02)ENQDSISSK 
$m / z=722.3239, \mathrm{z}=2,-10 \lg \mathrm{P}=53.63$, Carbamidomethylation $\mathrm{C}(+57.02)$

Error Map= Error Map shows the mass errors of matched fragment ions, with an error tolerance $\pm 0.8 \mathrm{Da}$. ms/ms spectrum

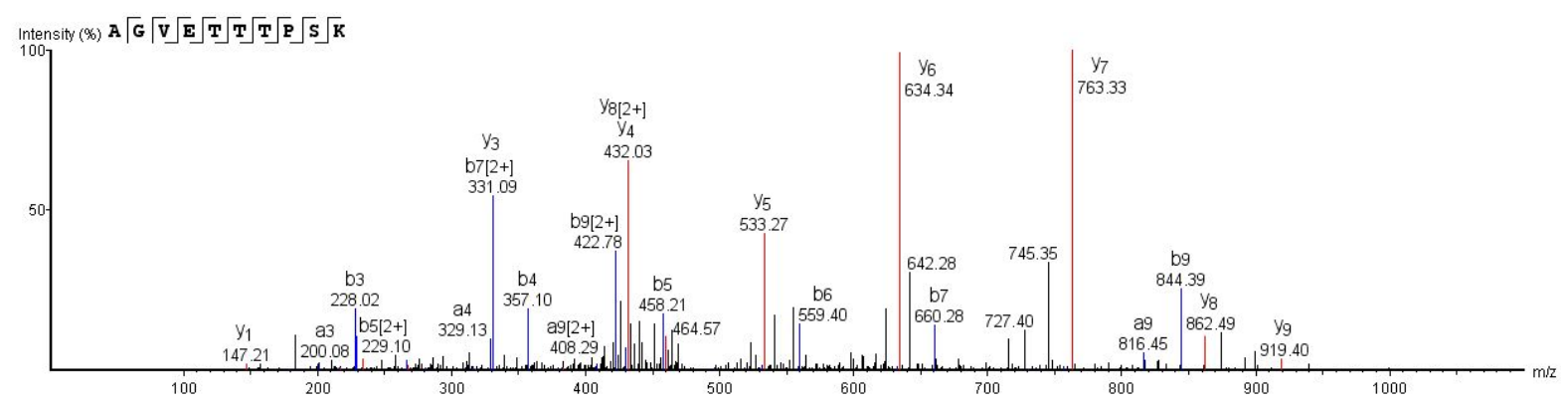

alignment spectrum view

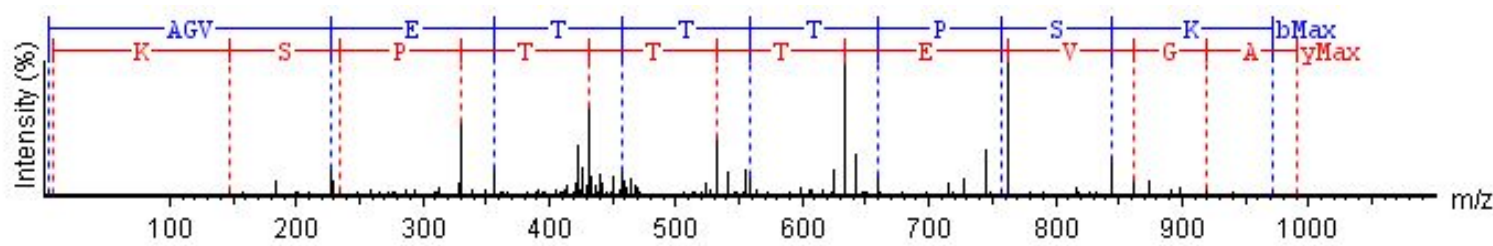

Ion $b$ and y Table and Error Map

\begin{tabular}{l|c|c|c|c|c|c|c|c|}
$\begin{array}{l}\text { \# } \\
\text { b }\end{array}$ & \multicolumn{1}{l}{$\mathrm{a}$} & $\mathrm{b}(2+)$ & $\mathrm{a}(2+)$ & \multicolumn{2}{l}{ Seq } & $y$ & $y(2+)$ & $\#$ \\
1 & 72.04 & 44.05 & 36.52 & 22.52 & $\mathrm{~A}$ & & & 10 \\
\hline 2 & 129.07 & 101.07 & 65.03 & 51.04 & G & 919.40 & 460.07 & 9 \\
\hline 3 & 228.02 & 200.08 & 114.57 & 100.57 & V & 862.49 & 432.03 & 8 \\
\hline 4 & 357.10 & 329.13 & 179.01 & 165.09 & E & 763.33 & 382.83 & 7 \\
\hline 5 & 458.21 & 430.21 & 229.10 & 216.14 & T & 634.34 & 317.89 & 6 \\
\hline 6 & 559.40 & 531.33 & 280.43 & 266.11 & T & 533.27 & 267.37 & 5 \\
\hline 7 & 660.28 & 632.62 & 331.09 & 316.23 & T & 432.03 & 217.25 & 4 \\
\hline 8 & 756.90 & 730.10 & 379.24 & 364.81 & P & 331.09 & 166.10 & 3 \\
\hline 9 & 844.39 & 816.45 & 422.78 & 408.29 & S & 234.19 & 117.57 & 2 \\
\hline 10 & & & & & K & 147.21 & 74.06 & 1 \\
\hline
\end{tabular}

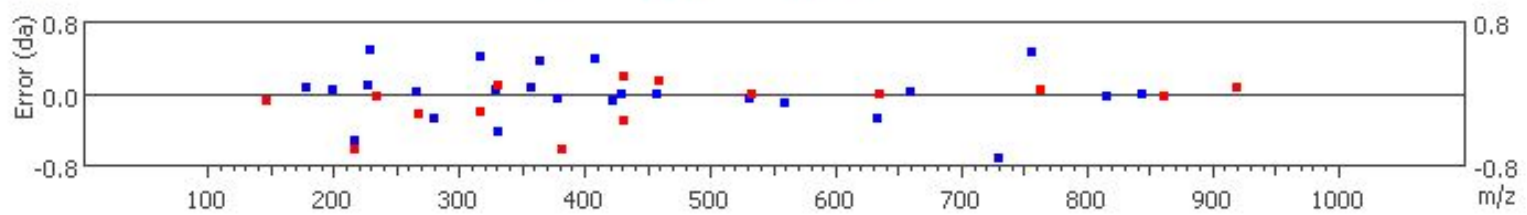

Figure S2. Spectral information: Immunoglobin G (Homo Sapiens)- AGVETTTPSK

$m / z=495.7588, \mathrm{z}=2,-10 \lg \mathrm{P}=48.51$ 
Error Map= Error Map shows the mass errors of matched fragment ions, with an error tolerance $\pm 0.8 \mathrm{Da}$.

\section{$\mathrm{ms} / \mathrm{ms}$ spectrum}

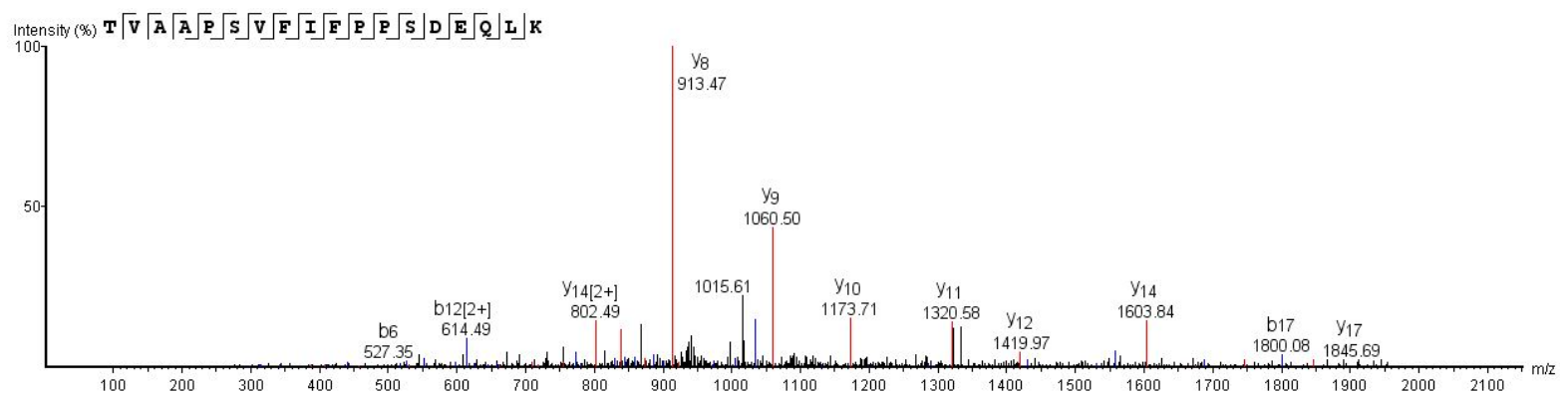

alignment spectrum view

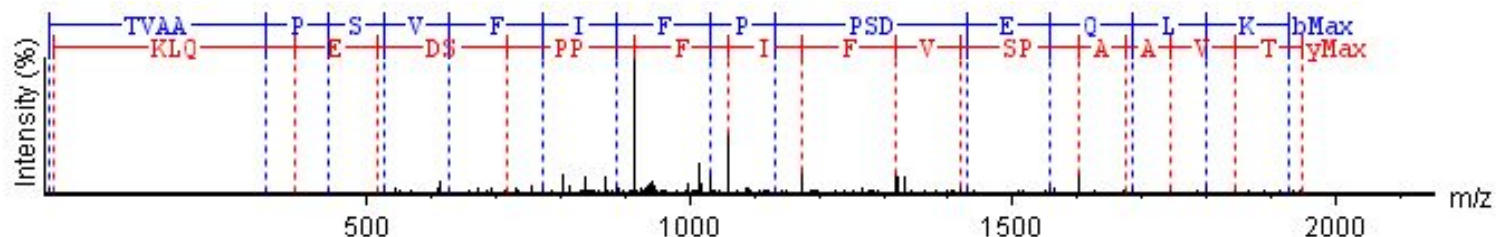

Ion $b$ and y Table and Error Map

\begin{tabular}{|c|c|c|c|c|c|c|c|c|}
\hline \# & b & a & $b(2+)$ & $a(2 t)$ & Seq & $y$ & $y(2+)$ & $\#$ \\
\hline 1 & 102.06 & 74.06 & 51.53 & 37.53 & T & & & 18 \\
\hline 2 & 201.12 & 173.13 & 101.06 & 87.06 & V & 1845.69 & 922.68 & 17 \\
\hline 3 & 272.16 & 244.17 & 136.58 & 122.58 & A & 1745.57 & 873.61 & 16 \\
\hline 4 & 342.48 & 315.45 & 172.10 & 158.10 & A & 1675.67 & 838.37 & 15 \\
\hline 5 & 440.47 & 412.34 & 220.63 & 206.63 & $\mathrm{P}$ & 1603.84 & 802.49 & 14 \\
\hline 6 & 527.35 & 499.29 & 264.14 & 250.14 & $S$ & 1506.78 & 754.55 & 13 \\
\hline 7 & 626.39 & 598.44 & 313.18 & 299.32 & V & 1419.97 & 709.58 & 12 \\
\hline 8 & 773.48 & 745.42 & 387.21 & 373.21 & $\mathrm{~F}$ & 1320.58 & 661.46 & 11 \\
\hline 9 & 886.57 & 858.72 & 443.75 & 429.75 & I & 1173.71 & 587.42 & 10 \\
\hline 10 & 1033.70 & 1004.85 & 517.40 & 503.29 & $\mathrm{~F}$ & 1060.50 & 530.30 & 9 \\
\hline 11 & 1130.54 & 1102.63 & 565.81 & 552.33 & $P$ & 913.47 & 457.14 & 8 \\
\hline 12 & 1227.68 & 1198.92 & 614.49 & 600.34 & $P$ & 816.41 & 408.39 & 7 \\
\hline 13 & 1314.71 & 1286.49 & 658.50 & 644.39 & $S$ & 718.72 & 360.18 & 6 \\
\hline 14 & 1430.01 & 1401.74 & 715.92 & 701.37 & D & 632.32 & 316.66 & 5 \\
\hline 15 & 1558.79 & 1531.13 & 779.78 & 765.89 & $E$ & 517.40 & 259.15 & 4 \\
\hline 16 & 1686.85 & 1658.84 & 844.03 & 830.15 & Q & 388.45 & 194.63 & 3 \\
\hline 17 & 1800.08 & 1771.93 & 900.68 & 886.57 & $\mathrm{~L}$ & 260.20 & 130.60 & 2 \\
\hline 18 & & & & & K & 147.11 & 74.06 & 1 \\
\hline
\end{tabular}

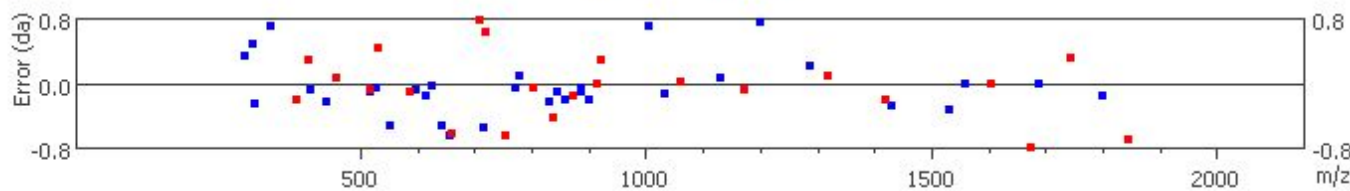

Figure S3. Spectral information: Immunoglobin Kappa constant (Homo Sapiens)-

TVAAPSVFIFPPSDEQLK $m / z=973.5176, \mathrm{z}=2,-10 \lg \mathrm{P}=40.98$ 
Error Map= Error Map shows the mass errors of matched fragment ions, with an error tolerance $\pm 0.8 \mathrm{Da}$.

ms/ms spectrum

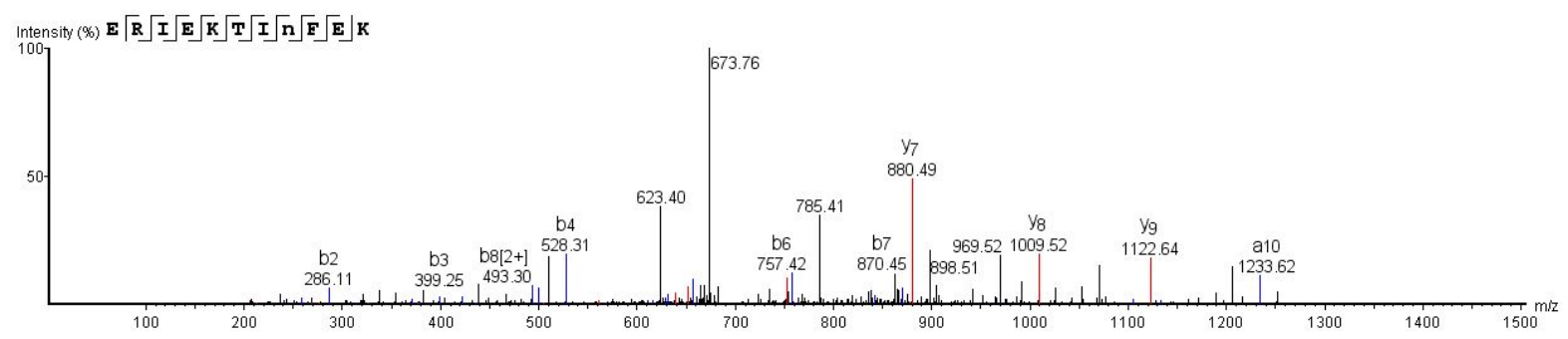

alignment spectrum view

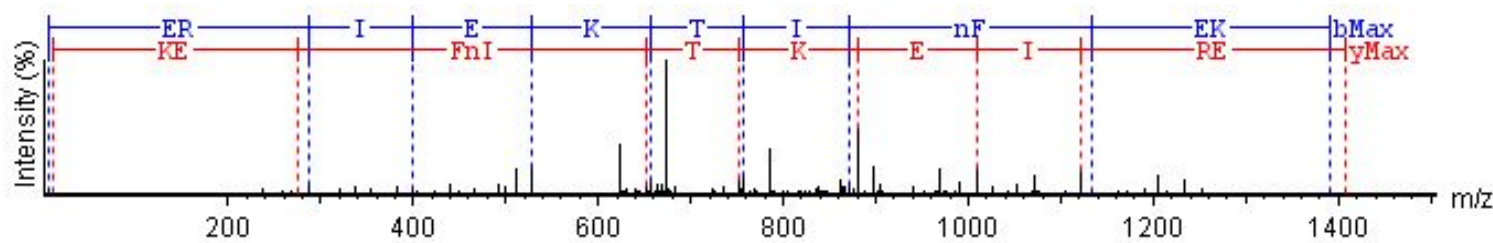

Ion $b$ and y Table and Error Map

\begin{tabular}{l|l|l|l|l|l|l|l|l|}
$\begin{array}{l}\text { \# } \\
\text { b }\end{array}$ & a & b $(2+)$ & $a(2+)$ & Seq & $y$ & $y(2+)$ & $\#$ \\
1 & 130.05 & 102.06 & 65.53 & 51.53 & E & & & 11 \\
\hline 2 & 286.11 & 258.23 & 143.58 & 129.58 & R & 1278.71 & 639.65 & 10 \\
\hline 3 & 399.25 & 371.42 & 200.12 & 186.12 & I & 1122.64 & 561.80 & 9 \\
\hline 4 & 528.31 & 500.31 & 265.26 & 251.25 & E & 1009.52 & 505.59 & 8 \\
\hline 5 & 656.37 & 628.40 & 329.42 & 314.40 & K & 880.49 & 440.74 & 7 \\
\hline 6 & 757.42 & 729.43 & 379.04 & 365.21 & T & 752.41 & 377.31 & 6 \\
\hline 7 & 870.45 & 842.52 & 435.72 & 422.20 & I & 651.34 & 326.60 & 5 \\
\hline 8 & 985.53 & 958.32 & 493.30 & 479.27 & N(+.98) & 538.25 & 269.09 & 4 \\
\hline 9 & 1132.72 & 1104.77 & 567.33 & 552.80 & F & 423.22 & 212.13 & 3 \\
\hline 10 & 1261.64 & 1233.62 & 631.47 & 616.65 & E & 276.28 & 138.58 & 2 \\
\hline 11 & & & & & K & 147.11 & 74.06 & 1 \\
\hline
\end{tabular}

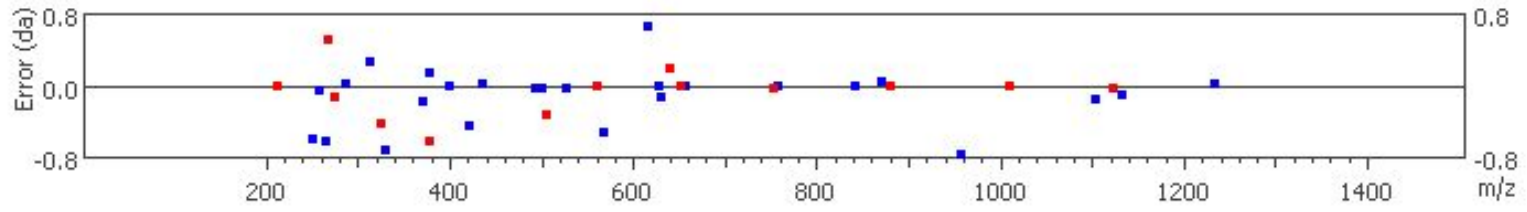

Figure S4. Spectral information: Ovoalbumin (fragment) (Gallus gallus) - ERIEKTIN(+.98)FEK $m / z=704.3644, \mathrm{z}=2,-10 \lg \mathrm{P}=19.61$, Deamidation $\mathrm{NQ}(+0.98)$

Error Map= Error Map shows the mass errors of matched fragment ions, with an error tolerance $\pm 0.8 \mathrm{Da}$. 
ms/ms spectrum

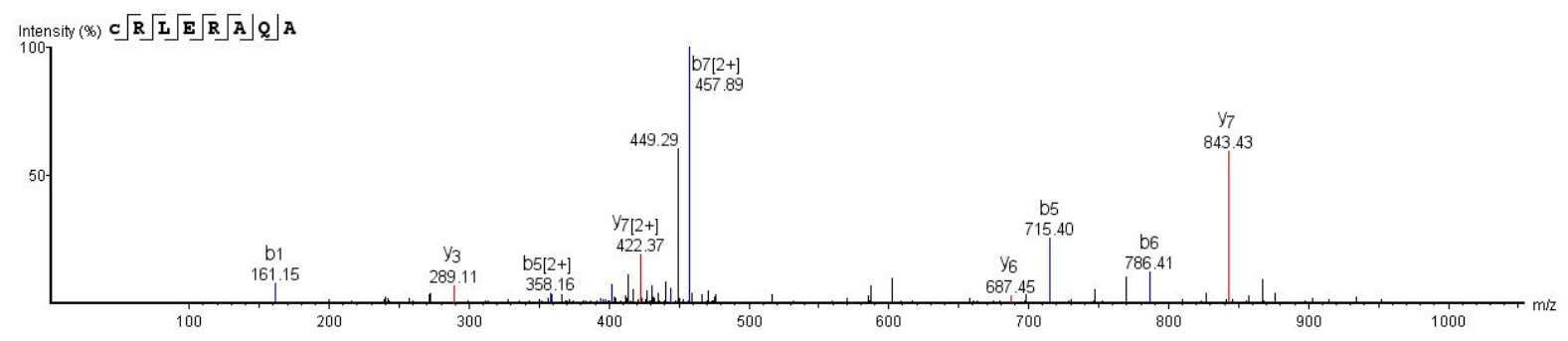

alignment spectrum view

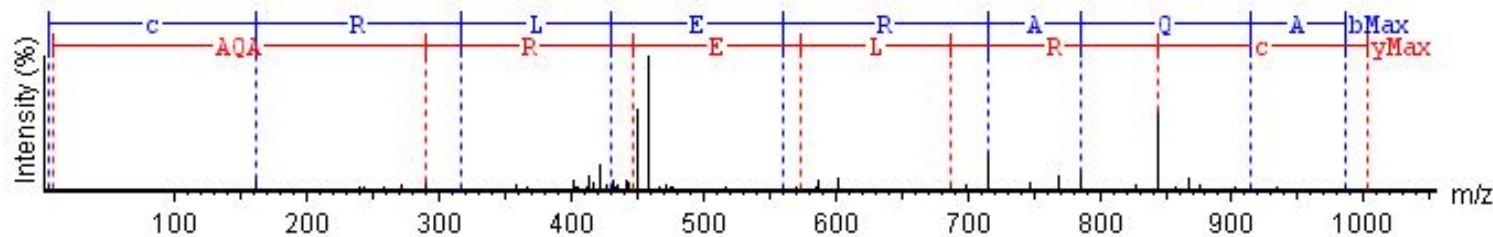

Ion $b$ and y Table and Error Map

\begin{tabular}{l|l|l|l|l|l|l|l|l|} 
\# & \multicolumn{1}{l}{$\mathrm{b}$} & \multicolumn{1}{l}{$\mathrm{a}$} & $\mathrm{b}(2+)$ & $\mathrm{a}(2+)$ & Seq & $y$ & $y(2+)$ & $\#$ \\
1 & 161.15 & 133.04 & 81.02 & 67.02 & $\mathrm{C}(+57.02)$ & & & 8 \\
\hline 2 & 316.99 & 289.11 & 159.07 & 145.07 & $\mathrm{R}$ & 843.43 & 422.37 & 7 \\
\hline 3 & 430.15 & 402.18 & 216.16 & 202.05 & L & 687.45 & 344.19 & 6 \\
\hline 4 & 559.50 & 531.33 & 280.13 & 266.24 & E & 574.03 & 288.28 & 5 \\
\hline 5 & 715.40 & 687.45 & 358.16 & 344.19 & R & 446.04 & 223.13 & 4 \\
\hline 6 & 786.41 & 758.65 & 393.57 & 380.25 & A & 289.11 & 145.08 & 3 \\
\hline 7 & 914.45 & 886.48 & 457.89 & 443.71 & Q & 218.11 & 109.56 & 2 \\
\hline 8 & & & & & A & 90.05 & 45.53 & 1 \\
\hline
\end{tabular}

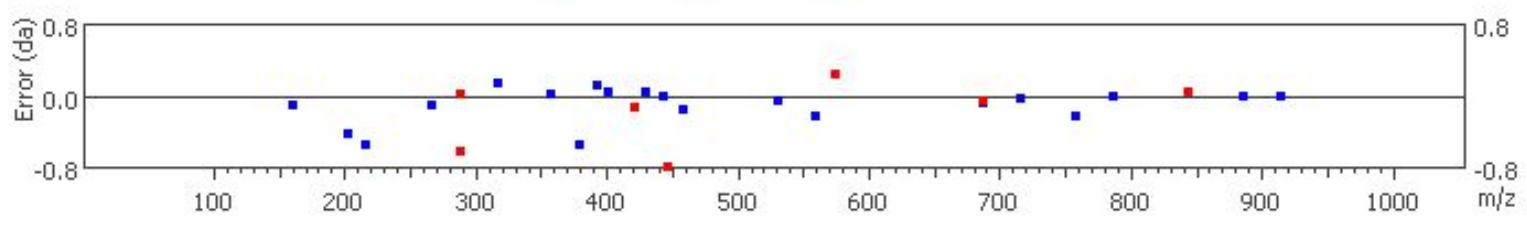

Figure S5. Spectral information: Ovomucoid (Aquila chrysaetos) -C(+57.02)RLERAQA $m / z=502.2533, \mathrm{z}=2,-10 \lg \mathrm{P}=20.57$, Carbamidomethylation $\mathrm{C}(+57.02)$

Error Map $=$ Error Map shows the mass errors of matched fragment ions, with an error tolerance $\pm 0.8 \mathrm{Da}$. 
ms/ms spectrum

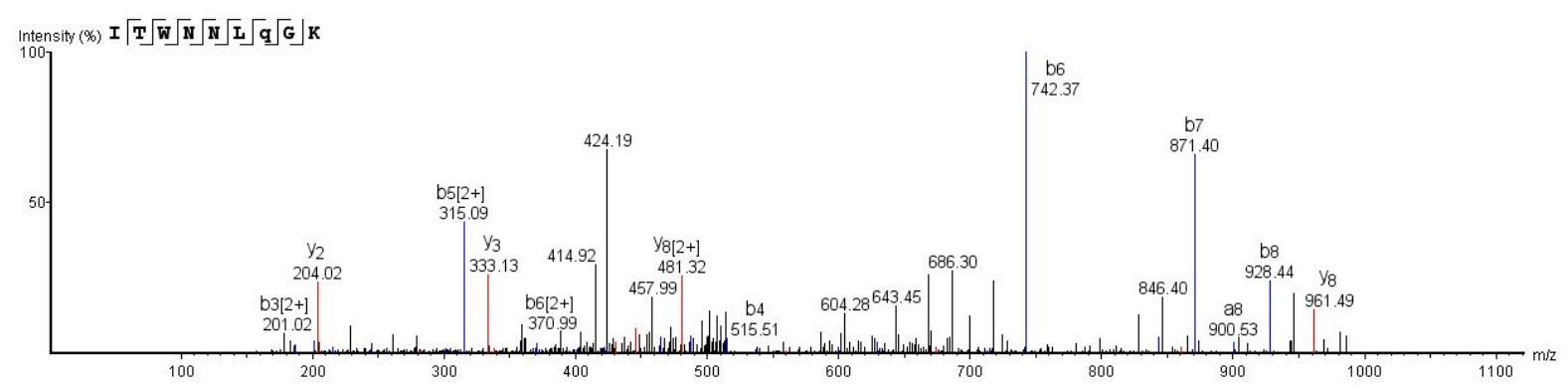

alignment spectrum view

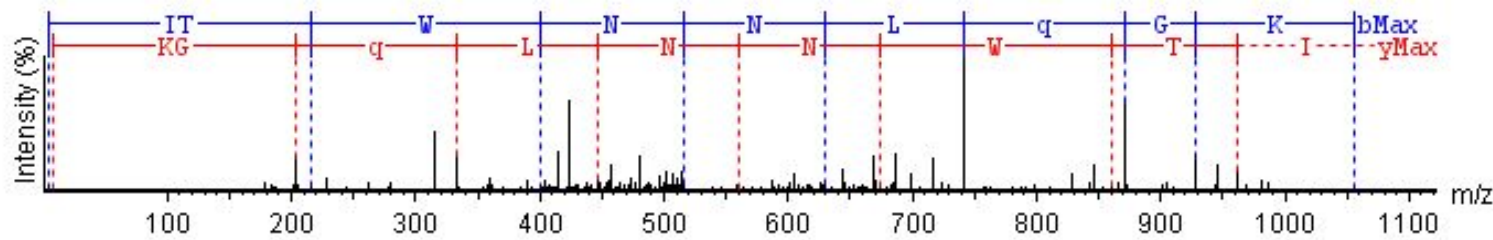

Ion $b$ and y Table and Error Map

\begin{tabular}{|c|c|c|c|c|c|c|c|c|}
\hline$\#$ & b & a & $b(2+)$ & $a(2+)$ & Seq & $y$ & $y(2+)$ & $\#$ \\
\hline 1 & 114.09 & 86.10 & 57.55 & 43.55 & I & & & 9 \\
\hline 2 & 215.52 & 187.16 & 108.07 & 94.07 & $T$ & 961.49 & 481.32 & 8 \\
\hline 3 & 400.70 & 372.56 & 201.02 & 187.16 & W & 860.62 & 430.92 & 7 \\
\hline 4 & 515.51 & 487.36 & 258.14 & 244.13 & $\mathrm{~N}$ & 673.64 & 338.34 & 6 \\
\hline 5 & 629.38 & 601.95 & 315.09 & 300.99 & $\mathrm{~N}$ & 559.65 & 280.90 & 5 \\
\hline 6 & 742.37 & 714.57 & 370.99 & 358.12 & L & 445.98 & 223.21 & 4 \\
\hline 7 & 871.40 & 843.55 & 436.22 & 422.09 & $Q(+.98)$ & 333.13 & 167.09 & 3 \\
\hline 8 & 928.44 & 900.53 & 464.52 & 450.73 & G & 204.02 & 102.57 & 2 \\
\hline 9 & & & & & K & 147.11 & 74.06 & 1 \\
\hline
\end{tabular}

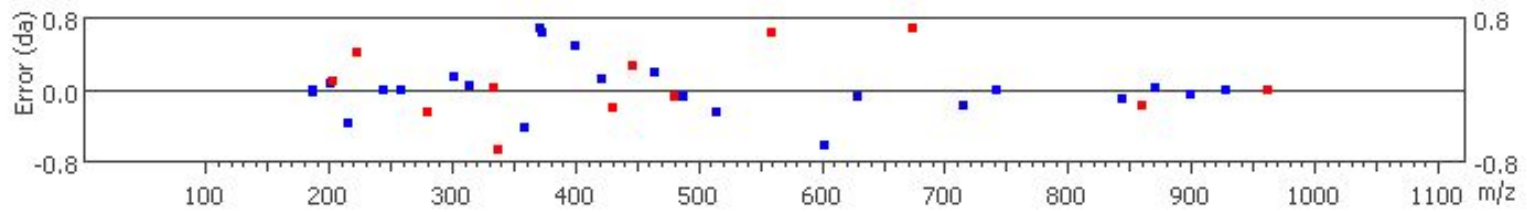

Figure S6. Spectral information: Ovotransferrin (Balearica regulorm gibbericeps)ITWNNLQ(+.98)GK $m / z=537.7748, \mathrm{z}=2,-10 \lg \mathrm{P}=23.96$, Deamidation $\mathrm{NQ}(+0.98)$

Error Map= Error Map shows the mass errors of matched fragment ions, with an error tolerance $\pm 0.8 \mathrm{Da}$. 
ms/ms spectrum

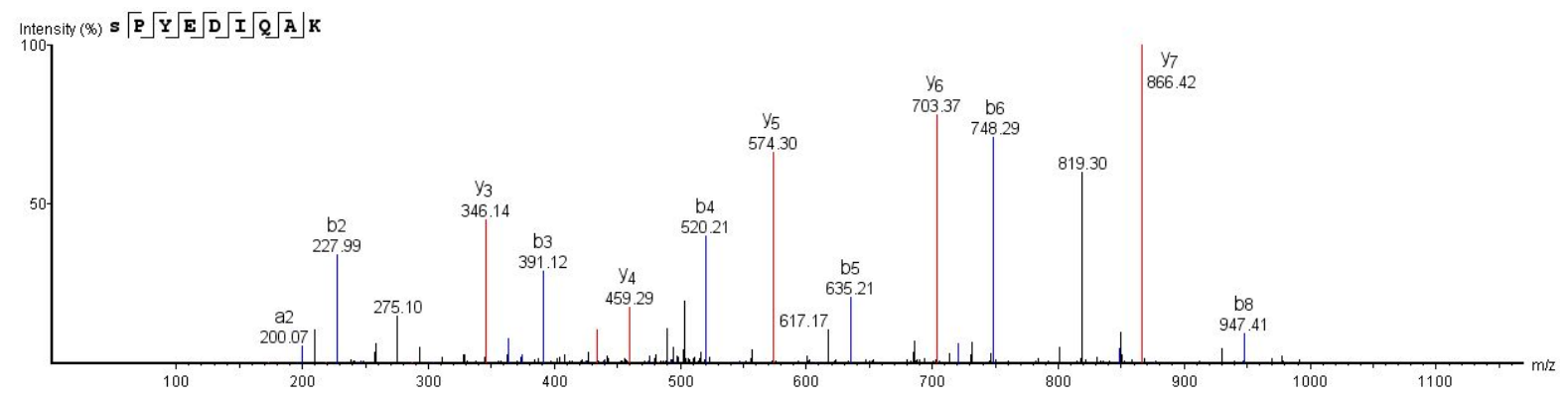

alignment spectrum view

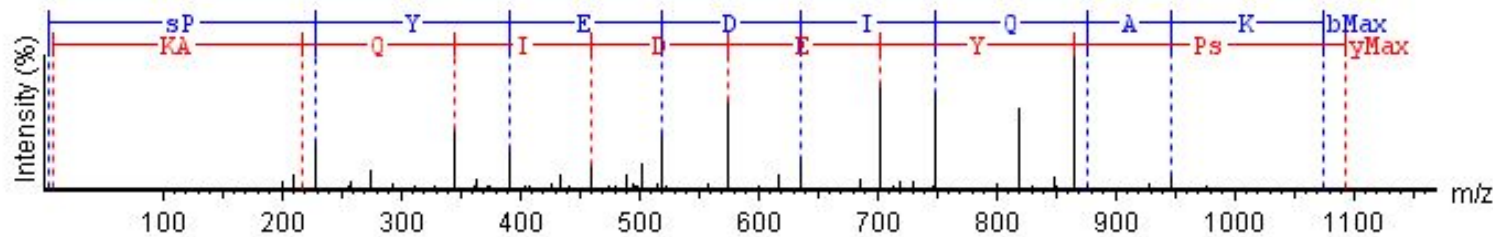

Ion $b$ and $y$ Table and Error Map

\begin{tabular}{|c|c|c|c|c|c|c|c|c|}
\hline \# & $b$ & a & $b(2+)$ & $a(2 t)$ & Seq & $y$ & $y(2+)$ & $\#$ \\
\hline 1 & 131.05 & 103.05 & 66.02 & 52.03 & $S(+43.01)$ & & & 9 \\
\hline 2 & 227.99 & 200.07 & 114.55 & 100.55 & $P$ & 963.48 & 482.41 & 8 \\
\hline 3 & 391.12 & 363.09 & 196.16 & 182.08 & $Y$ & 866.42 & 433.78 & 7 \\
\hline 4 & 520.21 & 492.30 & 260.60 & 246.90 & $E$ & 703.37 & 352.18 & 6 \\
\hline 5 & 635.21 & 607.38 & 318.12 & 304.22 & D & 574.30 & 287.12 & 5 \\
\hline 6 & 748.29 & 720.26 & 374.23 & 360.66 & I & 459.29 & 230.15 & 4 \\
\hline 7 & 876.47 & 848.42 & 438.53 & 424.55 & Q & 346.14 & 173.13 & 3 \\
\hline 8 & 947.41 & 919.42 & 474.25 & 460.21 & A & 218.24 & 109.57 & 2 \\
\hline 9 & & & & & K & 147.11 & 74.06 & 1 \\
\hline
\end{tabular}

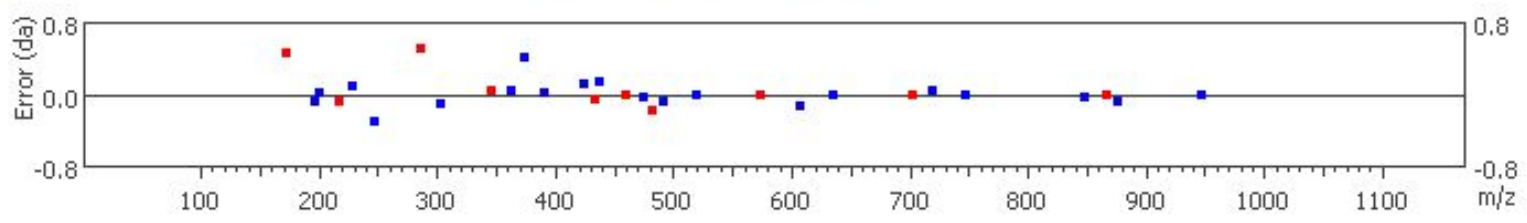

Figure S7. Spectral information: Vitellogenin-2 (Gallus gallus)- S(+43.01)PYEDIQAK

$\mathrm{m} / \mathrm{z}=547.2615, \mathrm{z}=2,-10 \lg \mathrm{P}=45.73$, Carbamylation any amino acid at $\mathrm{N}$-terminal $(+43.01)$

Error Map= Error Map shows the mass errors of matched fragment ions, with an error tolerance $\pm 0.8 \mathrm{Da}$. 
Table S1- Peptides with $-10 \lg P$ value $>19$ for each protein match listed in Table 1.

\begin{tabular}{|c|c|c|c|c|c|c|c|}
\hline $\begin{array}{l}\text { Protein } \\
\text { Name }\end{array}$ & Peptide & Unique & $-10 \lg P$ & Mass & $\begin{array}{l}\text { Area } \\
\text { SIMCA }\end{array}$ & PTM & AScore \\
\hline \multirow{8}{*}{ Serum albumin } & K.YIC(+57.02)ENQDSISSK.L & $\mathrm{Y}$ & 65.23 & 1442.635 & $2.79 \mathrm{E}+04$ & Carbamidomethylation & C3:Carbamidomethylation:1000.00 \\
\hline & K.LVNEVTEFAK.T & $\mathrm{Y}$ & 56.47 & 1148.608 & $5.37 \mathrm{E}+04$ & & \\
\hline & K.VFDEFKPLVEEPQNLIK.Q & $\mathrm{Y}$ & 53.35 & 2044.088 & $1.30 \mathrm{E}+05$ & & \\
\hline & K.KVPQVSTPTLVEVSR.N & $\mathrm{Y}$ & 49.54 & 1638.930 & $5.65 \mathrm{E}+04$ & & \\
\hline & K.TC $(+57.02)$ VADESAENC $(+57.02)$ DK & $\mathrm{Y}$ & 46.99 & 1497.571 & $5.65 \mathrm{E}+03$ & Carbamidomethylation & C3:Carbamidomethylation: 1000.00 \\
\hline & K.LDELRDEGK.A & $\mathrm{Y}$ & 42.20 & 1073.535 & $1.94 \mathrm{E}+04$ & & \\
\hline & K.AEFAEVSK.L & $\mathrm{Y}$ & 40.32 & 983.4811 & $2.52 E+04$ & & \\
\hline & K.TYETTLEK.C & $\mathrm{Y}$ & 25.10 & 889.4141 & $1.32 \mathrm{E}+04$ & & \\
\hline Immunoglobin G & K.AGVETTTPSK.Q & $\mathrm{Y}$ & 54.54 & 989.5029 & $7.66 \mathrm{E}+03$ & & \\
\hline \multirow{2}{*}{$\begin{array}{l}\text { Immunoglobin } \\
\text { Kappa constant }\end{array}$} & R.TVAAPSVFIFPPSDEQLK.S & $\mathrm{Y}$ & 71.90 & 1945.020 & $9.55 \mathrm{E}+03$ & & \\
\hline & K.VDNALQSGNSQESVTEQDSK.D & Y & 40.98 & 2134.961 & $1.32 \mathrm{E}+03$ & & \\
\hline $\begin{array}{l}\text { Ovoalbumin } \\
\text { (fragment) }\end{array}$ & L.ERIEKTIN(+.98)FEK.L & $\mathrm{Y}$ & 19.61 & 1406.741 & $3.81 E+05$ & Deamidation (NQ) & N8:Deamidation (NQ):1000.00 \\
\hline \multirow{4}{*}{ Ovomucoid } & K.C(+57.02)RLERAQA.L & $\mathrm{Y}$ & 28.90 & 1002.503 & $1.14 \mathrm{E}+05$ & Carbamidomethylation & C1:Carbamidomethylation: 1000.00 \\
\hline & K.PSSQGNSGRK.D & Y & 27.90 & 1016.499 & $2.44 \mathrm{E}+06$ & & \\
\hline & L.DNNSSNDINK.R & $\mathrm{Y}$ & 21.27 & 1119.479 & $1.31 \mathrm{E}+03$ & & \\
\hline & W.C(+57.02)VTPDGKPISGSSVQN(+.98)K.T & $\mathrm{Y}$ & 21.15 & 1773.857 & $6.32 \mathrm{E}+03$ & $\begin{array}{c}\text { Carbamidomethylation; Deamidation } \\
\text { (NQ) }\end{array}$ & $\begin{array}{l}\mathrm{C} 1: \text { Carbamidomethylation:1000.00; } \mathrm{N16} \text { :Dea } \\
\text { midation (NQ):0.00 }\end{array}$ \\
\hline \multirow{4}{*}{ Ovotransferrin } & D.ITWNNLQ(+.98)GK.K & $\mathrm{N}$ & 24.72 & 1073.551 & $9.61 \mathrm{E}+03$ & Deamidation (NQ) & Q7:Deamidation (NQ):20.50 \\
\hline & G.KDSSSIEQGEVGTSEIN(+.98)GLM(+15.99)C(+57.02)LK.D & $\mathrm{Y}$ & 23.96 & 2498.152 & $1.60 \mathrm{E}+05$ & $\begin{array}{l}\text { Deamidation (NQ); Oxidation (M); } \\
\text { Carbamidomethylation }\end{array}$ & $\begin{array}{c}\text { N17:Deamidation (NQ):0.00;M20:Oxidation } \\
\text { (M):1000.00;C21:Carbamidomethylation:10 } \\
00.00\end{array}$ \\
\hline & V.ALC(+57.02)FAAPPKASIK.W & $\mathrm{N}$ & 23.13 & 1372.754 & $1.28 \mathrm{E}+04$ & Carbamidomethylation & C3:Carbamidomethylation: 1000.00 \\
\hline & K.DSSSIEQGEVGT(+79.97)SEINGLMC(+57.02)LKDGKGDVAFVK(-.98).H & Y & 22.82 & 3448.589 & $6.08 E+05$ & $\begin{array}{c}\text { Phosphorylation (STY); } \\
\text { Carbamidomethylation; Amidation }\end{array}$ & $\begin{array}{c}\text { T12:Phosphorylation } \\
\text { (STY):11.06;C20:Carbamidomethylation:100 } \\
0.00 ; \mathrm{K} 32 \text { :Amidation:1000.00 }\end{array}$ \\
\hline
\end{tabular}




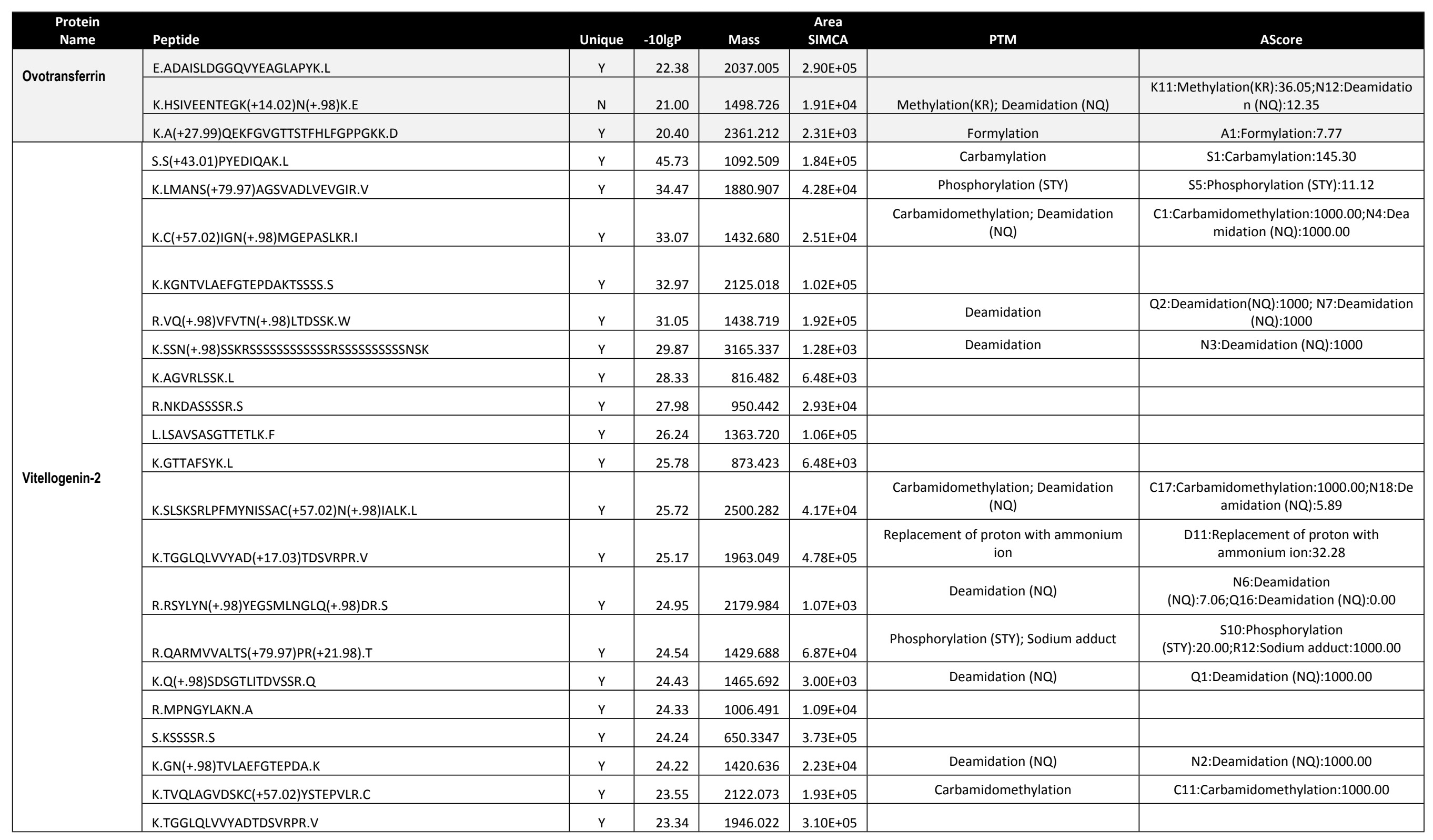




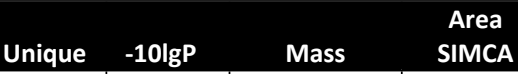

L.VM(+15.99)M(+15.99)KSAGEATNLK.A

K.LC(+57.02)ADASVRNAHK.A

R.Q(+.98)ARMVVALTSP(+31.99)R.T

R.GILN(+.98)M(+15.99)FQMTIK.K

G.HLNGSSSSSSSSR.S

\section{K.IAWKDPK.T}

R.MPMKFDAK.I

R.EETEIVVGR.H

Y.EDIQAK(+28.03)LK.R

R.QVYQISPFNE(+37.95)PTGVAVMEAR.Q

R.WLLSAVSASGTTETLK.F

Vitellogenin-2

\section{K.Q(+.98)IKELGKALQ.G}

R.SSSSSSSSSSSSRSSSSSSSSSSNSKSSSSSSK.S

\section{D.MHPVNGQVK.L}

K.SSSSRSS(-18.01)SSSSKS.S

F.AMQGPDSM(+31.99)PR.K

\section{K.LK(+28.03)QSDSGTLIT(+79.97)DVSSR.Q}

M.P(+31.99)NGYLAK.N

K.SSSSSSK(+28.03)SSSSS.S

\section{Q.IRNSIAGQ.W}

E.ENDQVKQAR.N

R.M(+15.99)VVALTSPR.T

K.D(+43.99)ASSSSRSSK.S

S.SSSSSKSSSSSSR.S

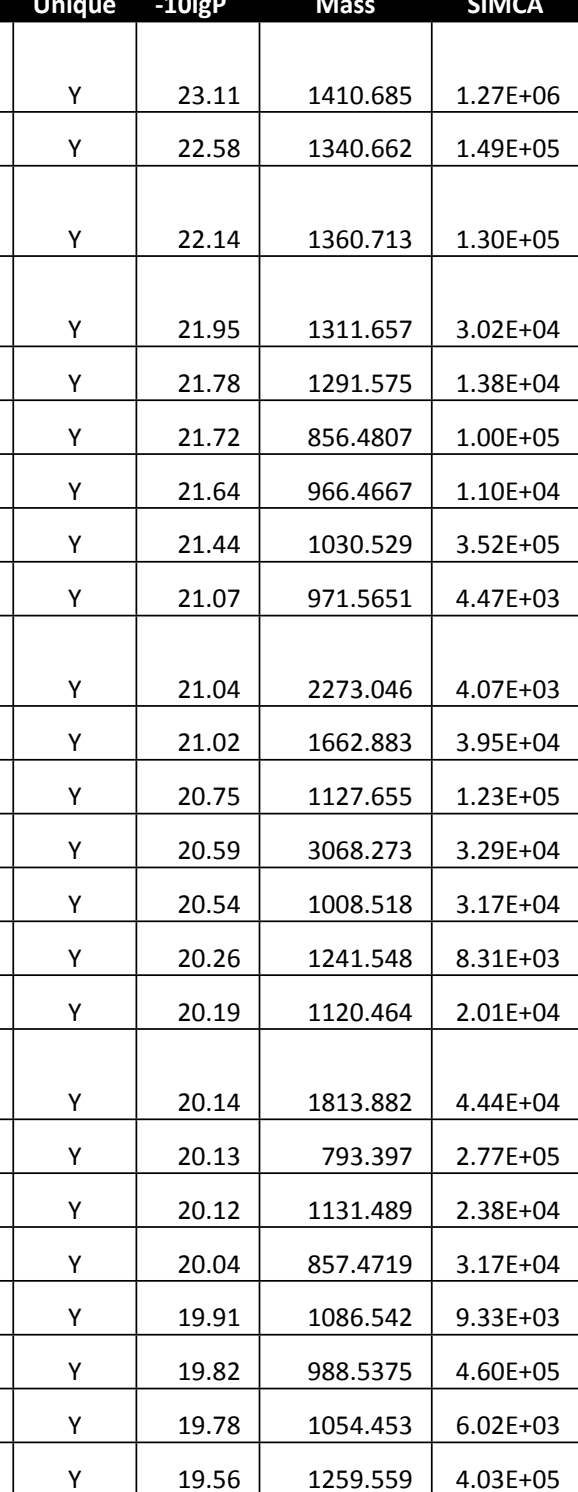

\begin{tabular}{|c|c|}
\hline PTM & AScore \\
\hline Oxidation (M) & $\begin{array}{l}\text { M2:Oxidation (M):1000.00;M3:Oxidation } \\
(\mathrm{M}): 1000.00\end{array}$ \\
\hline Carbamidomethylation & C2:Carbamidomethylation: 1000.00 \\
\hline Deamidation (NQ); Dihydroxy & $\begin{array}{c}\text { Q1:Deamidation } \\
\text { (NQ):1000.00;P11:Dihydroxy:17.01 }\end{array}$ \\
\hline Deamidation (NQ); Oxidation (M) & $\begin{array}{l}\text { N4:Deamidation (NQ):9.42;M5:Oxidation } \\
\text { (M):16.66 }\end{array}$ \\
\hline & \\
\hline & \\
\hline Dimethylation(KR) & K6:Dimethylation(KR):60.92 \\
\hline Replacement of 2 protons by calcium & $\begin{array}{l}\text { E10:Replacement of } 2 \text { protons by } \\
\text { calcium: } 19.48\end{array}$ \\
\hline Deamidation (NQ) & Q1:Deamidation (NQ):53.33 \\
\hline Dehydration & S7:Dehydration:0.00 \\
\hline Sulphone & M8:Sulphone:13.13 \\
\hline Dimethylation(KR); Phosphorylation (STY) & $\begin{array}{c}\text { K2:Dimethylation(KR):82.99;T11:Phosphory } \\
\text { ation (STY):0.00 }\end{array}$ \\
\hline Dihydroxy & P1:Dihydroxy:61.77 \\
\hline Dimethylation(KR) & K7:Dimethylation(KR):1000.00 \\
\hline Oxidation (M) & M1:Oxidation (M):1000.00 \\
\hline Carboxylation (DKW) & D1:Carboxylation (DKW):14.78 \\
\hline
\end{tabular}




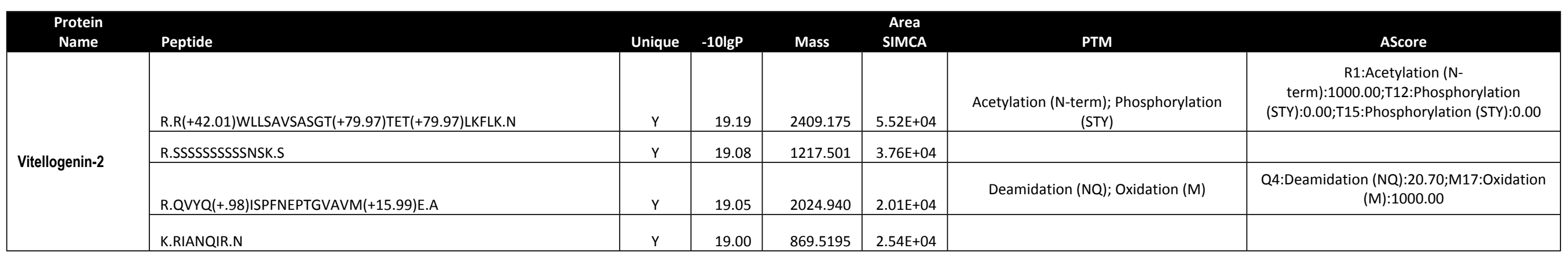


Table S2 - Results of the search with UNIPROT ALL PROTEINS database

\begin{tabular}{|c|c|c|c|c|c|c|c|c|}
\hline $\begin{array}{l}\text { Protein } \\
\text { accession }\end{array}$ & $-10 \lg P$ & $\begin{array}{l}\text { Coverage } \\
(\%)\end{array}$ & $\begin{array}{l}\text { Peptides } \\
\text { intensity }\end{array}$ & \#Peptides & $\begin{array}{l}\text { \#Unique } \\
\text { Peptides }\end{array}$ & PTM & Avg. Mass & Protein Name \\
\hline P00761 & 242.58 & 94 & $4.88 \mathrm{E}+07$ & 105 & 58 & $\begin{array}{l}\text { Carbamidomethylation; Oxidation }(\mathrm{M}) \text {; Deamidation }(\mathrm{NQ}) \text {; } \\
\text { Acetylation (N-term); Methylation(KR); } 2 \text { more }\end{array}$ & 24409 & Trypsin OS=Sus scrofa OX=9823 PE=1 SV=1 \\
\hline P35527 & 286.12 & 87 & $1.40 \mathrm{E}+08$ & 147 & 144 & $\begin{array}{l}\text { Carbamidomethylation; Oxidation (M); Deamidation (NQ); } \\
\text { Acetylation (N-term); Methylation(KR); } 2 \text { more }\end{array}$ & 62064 & $\begin{array}{c}\text { Keratin type I cytoskeletal } 9 \text { OS=Homo sapiens } \\
\text { OX=9606 GN=KRT9 PE=1 SV=3 }\end{array}$ \\
\hline P01040 & 130.06 & 84 & $7.32 \mathrm{E}+05$ & 9 & 9 & & 11006 & $\begin{array}{l}\text { Cystatin-A OS=Homo sapiens OX=9606 } \\
\text { GN=CSTA PE }=1 \text { SV }=1\end{array}$ \\
\hline P13645 & 245.19 & 77 & $2.00 \mathrm{E}+07$ & 77 & 45 & $\begin{array}{l}\text { Carbamidomethylation; Oxidation (M); Deamidation (NQ); } \\
\text { HydR; Acetylation (N-term); } 2 \text { more }\end{array}$ & 58827 & $\begin{array}{c}\text { Keratin type I cytoskeletal } 10 \mathrm{OS}=\text { Homo sapiens } \\
\mathrm{OX}=9606 \mathrm{GN}=\mathrm{KRT} 10 \mathrm{PE}=1 \mathrm{SV}=6\end{array}$ \\
\hline P35908 & 237.89 & 77 & $5.72 \mathrm{E}+06$ & 63 & 32 & $\begin{array}{l}\text { Carbamidomethylation; Oxidation (M); Deamidation (NQ); } \\
\text { Acetylation (N-term); Mutation }\end{array}$ & 65433 & $\begin{array}{l}\text { Keratin type II cytoskeletal } 2 \text { epidermal } \mathrm{OS}=\text { Homo } \\
\text { sapiens } \mathrm{OX}=9606 \mathrm{GN}=\mathrm{KRT} 2 \mathrm{PE}=1 \mathrm{SV}=2\end{array}$ \\
\hline Q04695 & 189.51 & 74 & $9.59 \mathrm{E}+05$ & 40 & 6 & $\begin{array}{c}\text { Carbamidomethylation; Oxidation (M); Deamidation (NQ); } \\
\text { Mutation }\end{array}$ & 48106 & $\begin{array}{c}\text { Keratin type I cytoskeletal } 17 \text { OS=Homo sapiens } \\
\text { OX=9606 GN=KRT17 PE=1 SV=2 }\end{array}$ \\
\hline P08779 & 209.58 & 72 & $6.48 \mathrm{E}+06$ & 49 & 24 & $\begin{array}{c}\text { Carbamidomethylation; Oxidation (M); Deamidation (NQ); } \\
\text { Mutation }\end{array}$ & 51268 & $\begin{array}{c}\text { Keratin type I cytoskeletal } 16 \text { OS=Homo sapiens } \\
\text { OX=9606 GN=KRT16 PE=1 SV=4 }\end{array}$ \\
\hline P04259 & 209.25 & 69 & $2.64 \mathrm{E}+05$ & 61 & 2 & $\begin{array}{l}\text { Carbamidomethylation; Oxidation (M); Deamidation (NQ); } \\
\text { Acetylation (N-term); Mutation }\end{array}$ & 60067 & $\begin{array}{c}\text { Keratin type II cytoskeletal 6B OS=Homo sapiens } \\
\text { OX=9606 GN=KRT6B PE }=1 \mathrm{SV}=5\end{array}$ \\
\hline P81605 & 109.2 & 69 & $3.22 \mathrm{E}+06$ & 10 & 10 & Carbamidomethylation & 11284 & $\begin{array}{c}\text { Dermcidin OS=Homo sapiens } \mathrm{OX}=9606 \mathrm{GN}=\mathrm{DCD} \\
\qquad \mathrm{PE}=1 \mathrm{SV}=2\end{array}$ \\
\hline P02533 & 195.57 & 63 & $5.65 \mathrm{E}+06$ & 45 & 8 & $\begin{array}{c}\text { Carbamidomethylation; Oxidation (M); Deamidation (NQ); } \\
\text { Mutation }\end{array}$ & 51562 & $\begin{array}{c}\text { Keratin type I cytoskeletal } 14 \mathrm{OS}=\text { Homo sapiens } \\
\text { OX=9606 GN=KRT14 PE=1 SV=4 }\end{array}$ \\
\hline
\end{tabular}




\begin{tabular}{|c|c|c|c|c|c|c|c|c|}
\hline $\begin{array}{l}\text { Protein } \\
\text { accession }\end{array}$ & $-10 \lg P$ & $\begin{array}{l}\text { Coverage } \\
(\%)\end{array}$ & $\begin{array}{l}\text { Peptides } \\
\text { intensity }\end{array}$ & \#Peptides & $\begin{array}{l}\text { \#Unique } \\
\text { Peptides }\end{array}$ & PTM & Avg. Mass & Protein Name \\
\hline P48668 & 207.29 & 62 & $6.21 \mathrm{E}+04$ & 61 & 2 & $\begin{array}{l}\text { Carbamidomethylation; Oxidation (M); Deamidation (NQ); } \\
\text { Acetylation (N-term); Mutation }\end{array}$ & 60025 & $\begin{array}{c}\text { Keratin type II cytoskeletal } 6 \mathrm{C} \text { OS=Homo sapiens } \\
\mathrm{OX}=9606 \mathrm{GN}=\mathrm{KRT} 6 \mathrm{C} \mathrm{PE}=1 \mathrm{SV}=3\end{array}$ \\
\hline P13647 & 192.04 & 50 & $1.57 \mathrm{E}+06$ & 50 & 4 & $\begin{array}{c}\text { Carbamidomethylation; Oxidation (M); Deamidation (NQ); } \\
\text { Mutation }\end{array}$ & 62378 & $\begin{array}{l}\text { Keratin type II cytoskeletal } 5 \mathrm{OS}=\text { Homo sapiens } \\
\mathrm{OX}=9606 \mathrm{GN}=\mathrm{KRT} 5 \mathrm{PE}=1 \mathrm{SV}=3\end{array}$ \\
\hline Q8NHM4 & 180.93 & 38 & $1.02 \mathrm{E}+05$ & 34 & 3 & $\begin{array}{c}\text { Carbamidomethylation; Deamidation (NQ); Acetylation (N- } \\
\text { term) }\end{array}$ & 26537 & $\begin{array}{l}\text { Putative trypsin- } 6 \text { OS=Homo sapiens } \mathrm{OX}=9606 \\
\mathrm{GN}=\mathrm{PRSS} 3 \mathrm{P} 2 \mathrm{PE}=5 \mathrm{SV}=2\end{array}$ \\
\hline Q6EIZ0 & 186.39 & 37 & $3.00 \mathrm{E}+05$ & 35 & 2 & Oxidation (M); Deamidation (NQ); Mutation & 57711 & $\begin{array}{l}\text { Keratin type I cytoskeletal } 10 \mathrm{OS}=\text { Canis lupus } \\
\text { familiaris } \mathrm{OX}=9615 \mathrm{GN}=\mathrm{KRT} 10 \mathrm{PE}=2 \mathrm{SV}=1\end{array}$ \\
\hline Q02SZ7 & 173.69 & 36 & $5.78 \mathrm{E}+06$ & 21 & 21 & Carbamidomethylation; Deamidation (NQ); Mutation & 48178 & $\begin{array}{l}\text { Lysyl endopeptidase OS=Pseudomonas } \\
\text { aeruginosa (strain UCBPP-PA14) OX=208963 } \\
\text { GN=prpL PE=1 SV=1 }\end{array}$ \\
\hline P08426 & 142.46 & 33 & $7.90 \mathrm{E}+05$ & 21 & 3 & $\begin{array}{l}\text { Carbamidomethylation; Deamidation (NQ); } \\
\text { Dimethylation(KR); Mutation }\end{array}$ & 26269 & $\begin{array}{l}\text { Cationic trypsin }-3 \text { OS=Rattus norvegicus } \\
\quad \mathrm{OX}=10116 \mathrm{GN}=\text { Try3 } \mathrm{PE}=2 \mathrm{SV}=1\end{array}$ \\
\hline Q9NZT1 & 102.82 & 31 & $6.75 \mathrm{E}+05$ & 4 & 4 & Deamidation (NQ); Acetylation (N-term) & 15893 & $\begin{array}{c}\text { Calmodulin-like protein } 5 \text { OS=Homo sapiens } \\
\text { OX }=9606 \mathrm{GN}=\mathrm{CALML} 5 \mathrm{PE}=1 \mathrm{SV}=2\end{array}$ \\
\hline P35326 & 60.75 & 31 & $4.21 \mathrm{E}+04$ & 2 & 2 & Carbamidomethylation & 7965 & $\begin{array}{l}\text { Small proline-rich protein } 2 \mathrm{~A} \text { OS=Homo sapiens } \\
\text { OX }=9606 \mathrm{GN}=\mathrm{SPRR} 2 \mathrm{~A} \mathrm{PE}=1 \mathrm{SV}=1\end{array}$ \\
\hline P05109 & 53.81 & 28 & $1.92 \mathrm{E}+03$ & 2 & 2 & Carbamidomethylation & 10835 & $\begin{array}{l}\text { Protein } \mathrm{S} 100-\mathrm{A} 8 \mathrm{OS}=\mathrm{Homo} \text { sapiens } \mathrm{OX}=9606 \\
\text { GN=S100A8 PE=1 SV=1 }\end{array}$ \\
\hline P22528 & 49.48 & 27 & $7.68 \mathrm{E}+04$ & 3 & 3 & Carbamidomethylation & 9888 & $\begin{array}{c}\text { Cornifin-B OS=Homo sapiens OX=9606 } \\
\text { GN=SPRR1B PE }=1 \text { SV }=2\end{array}$ \\
\hline P79179 & 80.84 & 24 & $3.34 \mathrm{E}+05$ & 4 & 4 & Carbamidomethylation & 16567 & $\begin{aligned} \text { Lysozyme C OS } & =\text { Gorilla gorilla gorilla OX=9595 } \\
\text { GN } & =L Y Z P E=2 \text { SV=1 }\end{aligned}$ \\
\hline
\end{tabular}




\begin{tabular}{|c|c|c|c|c|c|c|c|c|}
\hline $\begin{array}{l}\text { Protein } \\
\text { accession }\end{array}$ & $-10 \lg P$ & $\begin{array}{l}\text { Coverage } \\
(\%)\end{array}$ & $\begin{array}{l}\text { Peptides } \\
\text { intensity }\end{array}$ & \#Peptides & $\begin{array}{l}\text { \#Unique } \\
\text { Peptides }\end{array}$ & PTM & Avg. Mass & Protein Name \\
\hline P31151 & 61.65 & 24 & $2.33 E+04$ & 2 & 2 & Carbamidomethylation & 11471 & $\begin{array}{l}\text { Protein S100-A7 OS=Homo sapiens OX=9606 } \\
\text { GN=S100A7 PE=1 SV=4 }\end{array}$ \\
\hline P02810 & 63.41 & 23 & $8.24 \mathrm{E}+04$ & 3 & 3 & Deamidation (NQ) & 17016 & $\begin{array}{l}\text { Salivary acidic proline-rich phosphoprotein } 1 / 2 \\
\text { OS=Homo sapiens } \mathrm{OX}=9606 \mathrm{GN}=\mathrm{PRH} 1 \mathrm{PE}=1 \\
\mathrm{SV}=2\end{array}$ \\
\hline P23490 & 90.86 & 22 & $6.39 \mathrm{E}+04$ & 5 & 5 & Carbamidomethylation & 25761 & $\begin{array}{l}\text { Loricrin OS=Homo sapiens OX=9606 } \\
\text { GN=LORICRIN PE=1 SV=2 }\end{array}$ \\
\hline Q01469 & 71.79 & 22 & $9.00 \mathrm{E}+04$ & 4 & 4 & Carbamidomethylation & 15164 & $\begin{array}{l}\text { Fatty acid-binding protein } 5 \mathrm{OS}=\text { Homo sapiens } \\
\mathrm{OX}=9606 \mathrm{GN}=\mathrm{FABP} 5 \mathrm{PE}=1 \mathrm{SV}=3\end{array}$ \\
\hline A0A888 & 53.53 & 21 & $1.74 \mathrm{E}+04$ & 2 & 2 & & 16546 & $\begin{array}{l}\text { Prolactin-inducible protein homolog OS=Pongo } \\
\text { pygmaeus OX=9600 GN=PIP PE=3 SV=1 }\end{array}$ \\
\hline Q8N1N4 & 113.57 & 19 & $3.11 \mathrm{E}+04$ & 14 & 5 & Carbamidomethylation; Mutation & 56866 & $\begin{array}{c}\text { Keratin type II cytoskeletal } 78 \mathrm{OS}=\text { Homo sapiens } \\
\mathrm{OX}=9606 \mathrm{GN}=\mathrm{KRT} 78 \mathrm{PE}=1 \mathrm{SV}=2\end{array}$ \\
\hline P04406 & 95.2 & 18 & $4.96 \mathrm{E}+04$ & 5 & 5 & Deamidation (NQ) & 36053 & $\begin{array}{c}\text { Glyceraldehyde-3-phosphate dehydrogenase } \\
\text { OS=Homo sapiens OX=9606 GN=GAPDH PE=1 } \\
\text { SV=3 }\end{array}$ \\
\hline Q5T749 & 91.54 & 18 & $1.11 \mathrm{E}+05$ & 8 & 8 & Carbamidomethylation & 64136 & $\begin{array}{l}\text { Keratinocyte proline-rich protein } \mathrm{OS}=\mathrm{Homo} \\
\text { sapiens } \mathrm{OX}=9606 \mathrm{GN}=\mathrm{KPRP} P E=1 \mathrm{SV}=1\end{array}$ \\
\hline Q04118 & 88.02 & 18 & $1.14 \mathrm{E}+05$ & 5 & 4 & & 30980 & $\begin{array}{l}\text { Basic salivary proline-rich protein } 3 \text { OS=Homo } \\
\text { sapiens OX=9606 GN=PRB3 } P E=1 \mathrm{SV}=2\end{array}$ \\
\hline P0DOX7 & 73.64 & 18 & $9.55 E+03$ & 2 & 2 & & 23379 & $\begin{array}{c}\text { Immunoglobulin kappa light chain OS=Homo } \\
\text { sapiens OX=9606 PE=1 SV=1 }\end{array}$ \\
\hline P47929 & 66.32 & 18 & $4.05 E+04$ & 2 & 2 & & 15075 & $\begin{array}{l}\text { Galectin-7 OS=Homo sapiens OX=9606 } \\
\text { GN=LGALS7 PE=1 SV=2 }\end{array}$ \\
\hline
\end{tabular}




\begin{tabular}{|c|c|c|c|c|c|c|c|c|}
\hline $\begin{array}{l}\text { Protein } \\
\text { accession }\end{array}$ & $-10 \lg \mathrm{P}$ & $\begin{array}{l}\text { Coverage } \\
(\%)\end{array}$ & $\begin{array}{l}\text { Peptides } \\
\text { intensity }\end{array}$ & \#Peptides & $\begin{array}{l}\text { \#Unique } \\
\text { Peptides }\end{array}$ & PTM & Avg. Mass & Protein Name \\
\hline P04280 & 94.42 & 17 & $1.52 \mathrm{E}+05$ & 5 & 5 & & 38562 & $\begin{array}{l}\text { Basic salivary proline-rich protein } 1 \mathrm{OS}=\text { Homo } \\
\text { sapiens } \mathrm{OX}=9606 \mathrm{GN}=\mathrm{PRB} 1 \mathrm{PE}=1 \mathrm{SV}=3\end{array}$ \\
\hline P02754 & 57.08 & 17 & $3.17 \mathrm{E}+04$ & 2 & 2 & & 19883 & $\begin{array}{l}\text { Beta-lactoglobulin OS=Bos taurus OX=9913 } \\
\qquad \mathrm{GN}=\mathrm{LGB} P E=1 \mathrm{SV}=3\end{array}$ \\
\hline P15924 & 199.71 & 16 & $1.25 \mathrm{E}+06$ & 46 & 44 & Carbamidomethylation; Oxidation (M) & 331774 & $\begin{array}{c}\text { Desmoplakin OS=Homo sapiens OX=9606 } \\
\text { GN=DSP PE }=1 \text { SV=3 }\end{array}$ \\
\hline Q6P0K8 & 133.04 & 16 & $3.16 \mathrm{E}+05$ & 12 & 12 & Carbamidomethylation & 81801 & $\begin{array}{l}\text { Junction plakoglobin OS=Rattus norvegicus } \\
\quad \mathrm{OX}=10116 \mathrm{GN}=\mathrm{Jup} \mathrm{PE}=1 \mathrm{SV}=1\end{array}$ \\
\hline P02768 & 124.47 & 15 & $3.13 E+05$ & 8 & 8 & Carbamidomethylation & 69367 & $\begin{array}{l}\text { Serum albumin OS=Homo sapiens OX=9606 } \\
\qquad \mathrm{GN}=\mathrm{ALB} P E=1 \quad \mathrm{SV}=2\end{array}$ \\
\hline P10163 & 67.03 & 13 & $9.55 \mathrm{E}+04$ & 3 & 2 & & 31326 & $\begin{array}{l}\text { Basic salivary proline-rich protein } 4 \mathrm{OS}=\mathrm{Homo} \\
\text { sapiens } \mathrm{OX}=9606 \mathrm{GN}=\mathrm{PRB} 4 \mathrm{PE}=1 \mathrm{SV}=4\end{array}$ \\
\hline Q02413 & 124.01 & 12 & $4.44 \mathrm{E}+05$ & 11 & 11 & Carbamidomethylation; Oxidation (M); Mutation & 113748 & $\begin{array}{c}\text { Desmoglein-1 OS=Homo sapiens OX=9606 } \\
\text { GN=DSG1 PE=1 SV=2 }\end{array}$ \\
\hline Q5D862 & 89.88 & 10 & $1.56 \mathrm{E}+05$ & 6 & 6 & Carbamidomethylation & 248072 & $\begin{array}{l}\text { Filaggrin-2 OS=Homo sapiens } \mathrm{OX}=9606 \\
\qquad \mathrm{GN}=\mathrm{FLG} 2 \mathrm{PE}=1 \mathrm{SV}=1\end{array}$ \\
\hline Q7YR44 & 73.99 & 10 & $1.51 \mathrm{E}+05$ & 3 & 3 & Carbamidomethylation & 51611 & $\begin{array}{c}\text { Corneodesmosin OS=Pan troglodytes } \mathrm{OX}=9598 \\
\qquad \mathrm{GN}=\mathrm{CDSN} P E=2 \mathrm{SV}=1\end{array}$ \\
\hline
\end{tabular}

